Año 13.

Revista de Investigación

Núm. 33

Académica sin Frontera

ISSN: 2007-8870

\title{
http://revistainvestigacionacademicasinfrontera.com
}

Recibido el 10 de julio de 2020. Dictaminado mediante arbitraje favorablemente 14 de diciembre de 2020.

\section{FACTORES QUE INCIDEN EN LAS PREFERENCIAS DE LOS RADIOESCUCHAS DE LAS ESTACIONES DE RADIO ESTABLECIDAS EN LA CIUDAD DE NAVOJOA, SONORA MÉXICO.}

\author{
Dr. Gustavo César Hermosillo Anduaga \\ gustavocesar@gmail.com \\ 0RCID 0000-0002-4482-4058 \\ Dr. José César Kaplan Navarro \\ Jckaplan4@gmail.com \\ ORCID 0000-0002-1365-0569 \\ Mtro. Héctor Domínguez Ibarra \\ ORCID 0000-0002-1550-854X \\ hector_ybarra@hotmail.com
}

\section{Resumen}

La necesidad de medir y conocer los motivos reales del consumo de los contenidos informativos y de entretenimiento es una preocupación constante para medios, agencias y anunciantes. El aumento de la competencia en el sector radiofónico en México, ha dado como consecuencia que los empresarios contiendan tenazmente para atraer el mayor número de oyentes. En la ciudad de Navojoa, Sonora México se realizó una investigación de mercado para determinar las preferencias de los radioescuchas en relación a las opciones de radio disponibles en la ciudad. Se encontró que la radio más escuchada es la 103.3 llamada "la mejor”. La mayoría de los encuestados dijeron que escuchan radio de 3 a 5 días de la semana, normalmente por la mañana y lo hacen por lo menos una hora. La mayoría escucha en radio convencional, siendo su hogar el lugar donde más la oye. Finalmente, se encontró que los factores principales por las que escuchan radio son la música, las noticias y los locutores seguido por la variedad de programas.

\section{Palabras claves: Competencia, Gustos y Preferencias, Selección}


Año 13.

Revista de Investigación

Núm. 33

Académica sin Frontera

ISSN: 2007-8870

\title{
http://revistainvestigacionacademicasinfrontera.com
}

Recibido el 10 de julio de 2020. Dictaminado mediante arbitraje favorablemente 14 de diciembre de 2020.

\begin{abstract}
FACTORS THAT INFLUENCE THE PREFERENCES OF RADIO LISTENERS OF RADIO STATIONS ESTABLISHED IN THE CITY OF NAVOJOA, SONORA MEXICO

The need to measure and know the real reasons for the consumption of informational and entertainment content is a constant concern for media, agencies and advertisers. Increased competition in the radio sector in Mexico has resulted in businessmen tenaciously fighting to attract the largest number of listeners. In the city of Navojoa, Sonora Mexico, a market investigation was carried out to determine the preferences of listeners in relation to the radio options available in the city. It was found that the radio most listened to is 103.3 called the best. Most respondents said they listen to the radio 3-5 days a week, usually in the morning, and listen for at least an hour. Most listen to conventional radio, their home being the place where they hear it the most. Finally, it was found that the main factors why they listen to the radio are music, news and announcers, followed by the variety of programs.
\end{abstract}

Keywords: Competence, Tastes and Preferences, Selection 
Año 13.

Núm. 33

Académica sin Frontera

ISSN: 2007-8870

\section{http://revistainvestigacionacademicasinfrontera.com}

Recibido el 10 de julio de 2020. Dictaminado mediante arbitraje favorablemente 14 de diciembre de 2020.

\section{Introducción}

Los descubrimientos de Marconi, fueron la base para desarrollar, lo que hoy se conoce como radio. El proceso de radiodifusión se da en tres fases: Emisión o transmisión, propagación y recepción (Pinoargote, 2007). En México las primeras radiodifusoras vieron la luz en los años 20 del siglo pasado. En la actualidad su cobertura es de prácticamente del 100\% del territorio nacional (Mejía, 2007).

En el año 2016, el diario oficial de la federación, anunció licitación pública para la concesión de 191 frecuencias para la prestación del servicio público de radiodifusión sonora (Diario oficial de la Federación, 2016). Para el 13 de diciembre de 2018, en México se tenían autorizadas para su operación un total de 2,789 estaciones, distribuidas por servicio en: 389 estaciones de AM; 1,602 estaciones de FM, y 798 estaciones de TDT (Instituto Federal de Telecomunicaciones, 2018).

Los programadores de radio han tenido un particular interés en cuantificar a sus oyentes tratando de averiguar el tiempo de audición, En el mismo sentido, se interesan en conocer los motivos por los cuales escuchan una emisora, el grado de atención prestado y la opinión que les merece la programación (Portilla, 2004).

El propósito de esta investigación es determinar los gustos y preferencias de los radioescuchas de la ciudad de Navojoa, Sonora México y conocer cuáles son los factores que les hacen seleccionar una emisora como su preferida.

\section{Materiales y métodos}

Para este trabajo se hizo uso de la metodología propuesta por la investigación de mercados. Mediante estas investigaciones un empresario puede obtener información relevante sobre la 
Año 13.

Núm. 33

Académica sin Frontera

ISSN: 2007-8870

\section{http://revistainvestigacionacademicasinfrontera.com}

Recibido el 10 de julio de 2020. Dictaminado mediante arbitraje favorablemente 14 de diciembre de 2020.

opinión de sus clientes acerca de sus productos y/o servicios. La información recabada le ayudará a tomar decisiones que lo conduzcan a ser más competitivo, en un mercado altamente rivalizado. A mayor noción del comportamiento del mercado, mayor será la posibilidad de éxito (Fischer y Espejo, 2008).

Se aplicaron los pasos propuestos por Kinnear y Taylor (1998): Establecer la necesidad de información, especificar los objetivos de la investigación, determinar el diseño de la investigación y la fuente de datos, procedimiento de recolección de datos, diseño de la muestra, recolección, proceso, análisis de datos y presentación de resultados.

Para la presente investigación se desarrolló un enfoque cuantitativo. Se recopilaron datos para aplicarles un análisis estadístico, con el cual se determinaron los factores que toman en consideración los radioescuchas de Navojoa, Sonora al momento de seleccionar una emisora de radio. El sondeo fue no experimental, es decir, sin manipulación deliberada de las variables. Se basó fundamentalmente en la observación de fenómenos tal y como se dan en su contexto natural para analizarlos con posterioridad. La investigación fue transeccional de alcance descriptivo.

Los sujetos de investigación fueron los ciudadanos de la ciudad de Navojoa, divididos en tres segmentos: edades entre 15 a 29 años; de 30 a 45 años y de 45 años en adelante. La muestra fue de 290 elementos con nivel de confianza del 95\% con un margen de error del $6 \%$.

Se elaboró un cuestionario estructurado con preguntas dicotómicas y de opción múltiple. Asimismo, se incluyó una sección de preguntas en escala Likert y preguntas con una escala de medición ordinal o jerarquización. El tipo de muestro fue no probabilístico aleatorio. 
"Fl siber dite mis hijos

Año 13.

Núm. 33
Revista de Investigación

Académica sin Frontera

ISSN: 2007-8870

\section{http://revistainvestigacionacademicasinfrontera.com}

Recibido el 10 de julio de 2020. Dictaminado mediante arbitraje favorablemente 14 de diciembre de 2020.

\section{Resultados}

Figura 1. ¿Escucha la radio?

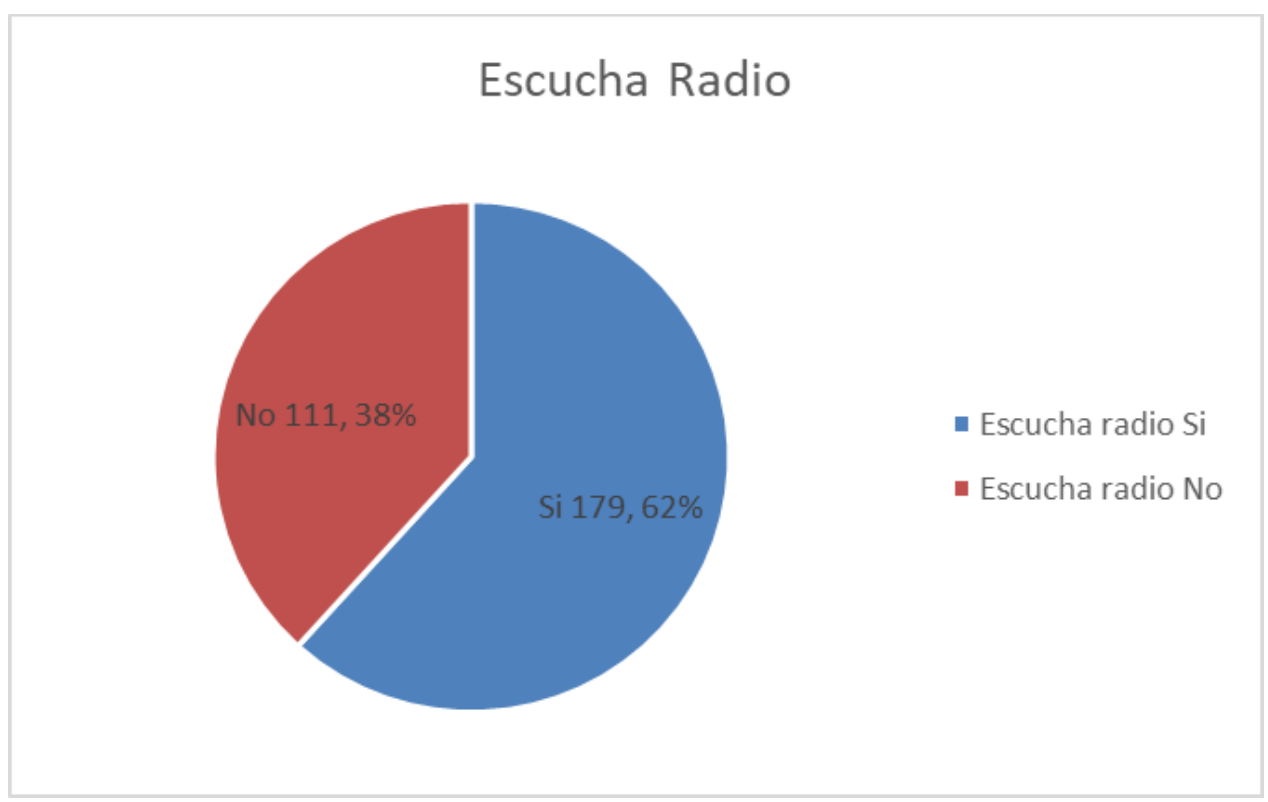

Fuente: Elaboración propia en base al Instrumento de investigación aplicado del 7 al 18 de Marzo del 2020, en Navojoa Sonora

Como se observa en la figura 1 , del total de los entrevistados el $62 \%$ escucha radio, siendo el sector femenino que mayormente lo hace. El segmento más numeroso que escucha radio en Navojoa, fue el de rango de edad entre 30 a 45 años con el 46.36\%, seguido por el de más de 45 años con un $31.84 \%$ y los que menos escuchan radio fue el segmento entre 15 a 29 años con apenas el 21.78\%. De los encuestados que admitieron no escuchar radio, comentaron que no les agradan los programas actuales, que prefieren las redes sociales para informarse y algunos comentaron que no tienen tiempo para oírlo. 
"Fil owher ide mis hijos

Año 13.

Núm. 33
Revista de Investigación

Académica sin Frontera

ISSN: 2007-8870

\section{http://revistainvestigacionacademicasinfrontera.com}

Recibido el 10 de julio de 2020. Dictaminado mediante arbitraje favorablemente 14 de diciembre de 2020.

\section{Figura 2 ¿Cuántas veces a la semana escucha radio?}

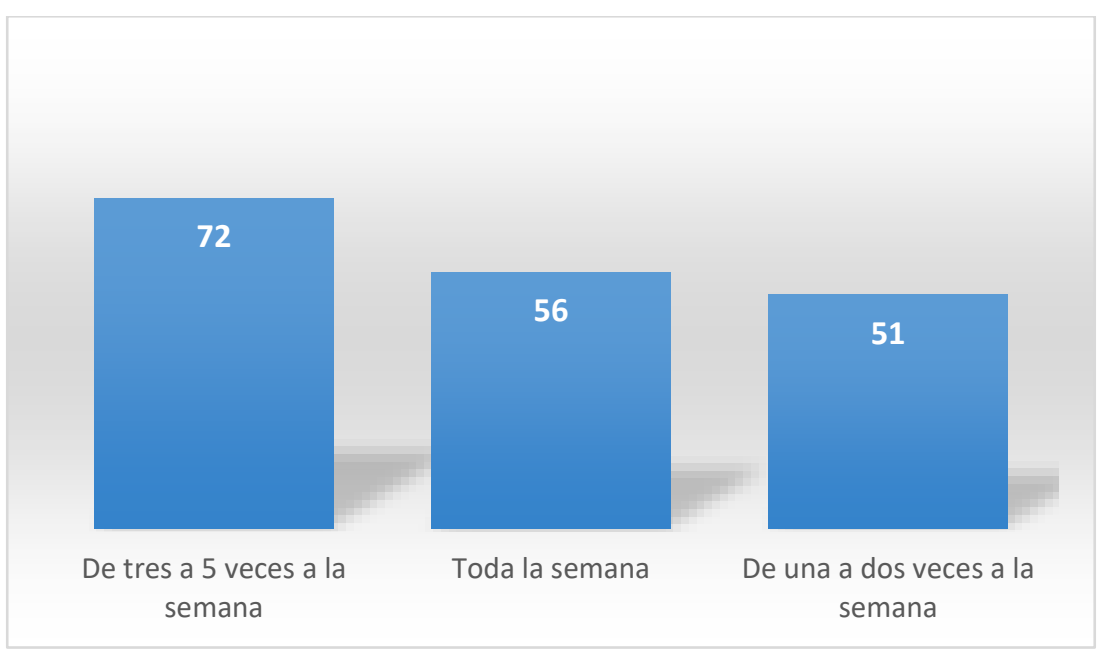

Fuente: Elaboración propia en base al Instrumento de investigación aplicado del 7 al 18 de

Marzo del 2020, en Navojoa Sonora

En la figura 2 se observa que el $40 \%$ de los entrevistados que sí escuchan radio, contestó que oye radio de tres a cinco veces por semana, seguido por el 30\% que lo escucha toda la semana. 
"Fl siber dite mis hijos

Año 13.

Núm. 33
Revista de Investigación Académica sin Frontera ISSN: 2007-8870

http://revistainvestigacionacademicasinfrontera.com

Recibido el 10 de julio de 2020. Dictaminado mediante arbitraje favorablemente 14 de diciembre de 2020.

Figura 3 ¿En qué momento del día escucha más radio?

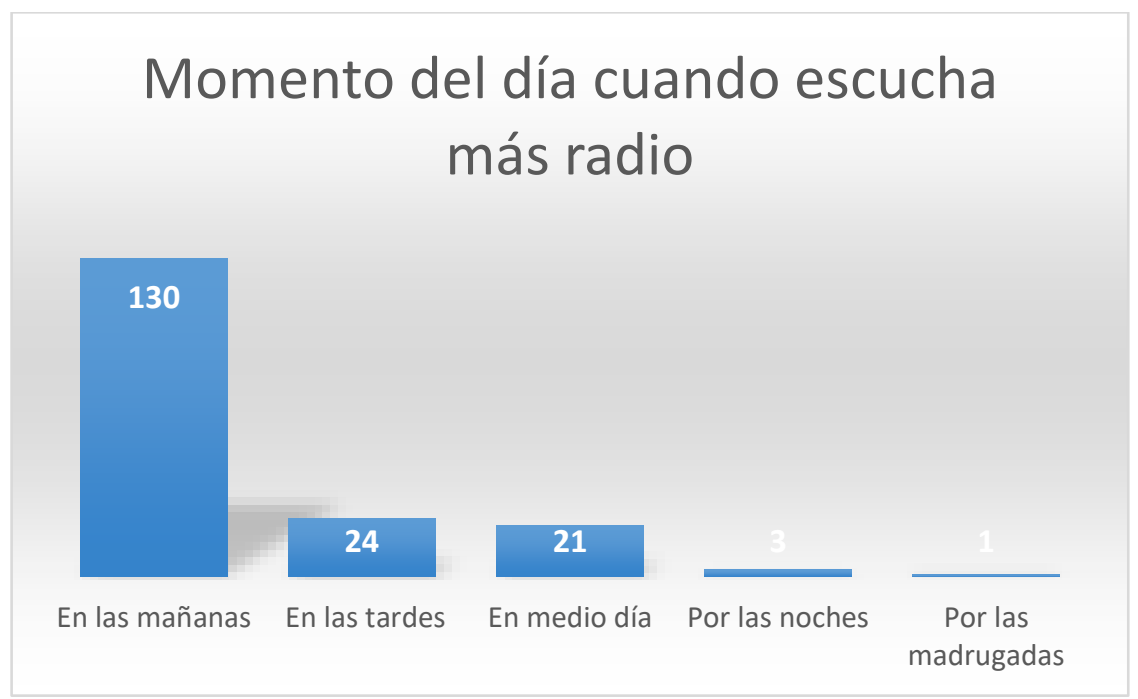

Fuente: Elaboración propia en base al Instrumento de investigación aplicado del 7 al 18 de Marzo del 2020, en Navojoa Sonora.

En la figura 3 se observa que de los que sí escuchan radio, el $72.6 \%$ escuchan la radio de preferencia por la mañana, el $25 \%$ lo hace en medio día y por la tarde. El restante $3 \%$ lo escucha por las noches y madrugadas. 
"Fl siler dite min hijos

Año 13.

Núm. 33
Revista de Investigación

Académica sin Frontera

ISSN: 2007-8870

http://revistainvestigacionacademicasinfrontera.com

Recibido el 10 de julio de 2020. Dictaminado mediante arbitraje favorablemente 14 de diciembre de 2020.

Figura 4 ¿Cuántas horas escucha la radio?

Número de horas que escucha radio en el día

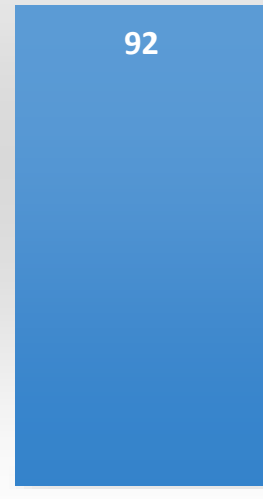

una hora al dia

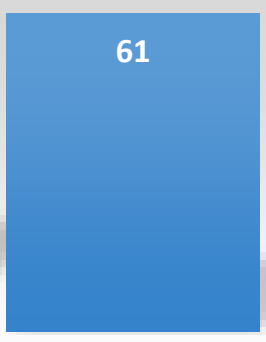

dos a tres horas al dia

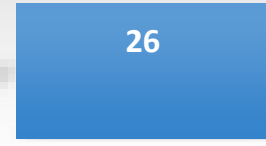

mas de cinco horas al dia

Fuente: Elaboración propia en base al Instrumento de investigación aplicado del 7 al 18 de Marzo del 2020, en Navojoa Sonora.

En relación al número de horas que los entrevistados informaron que escuchan la radio el $51 \%$ informa que la oye por lo menos una hora cada día, el 34\% dos a tres horas al día y el 14 más de cinco horas por día-. 
Año 13.

Revista de Investigación

Núm. 33

Académica sin Frontera

ISSN: 2007-8870

\section{http://revistainvestigacionacademicasinfrontera.com}

Recibido el 10 de julio de 2020. Dictaminado mediante arbitraje favorablemente 14 de diciembre de 2020.

\section{Figura 5 ¿Por cuál medio escuchas radio?}

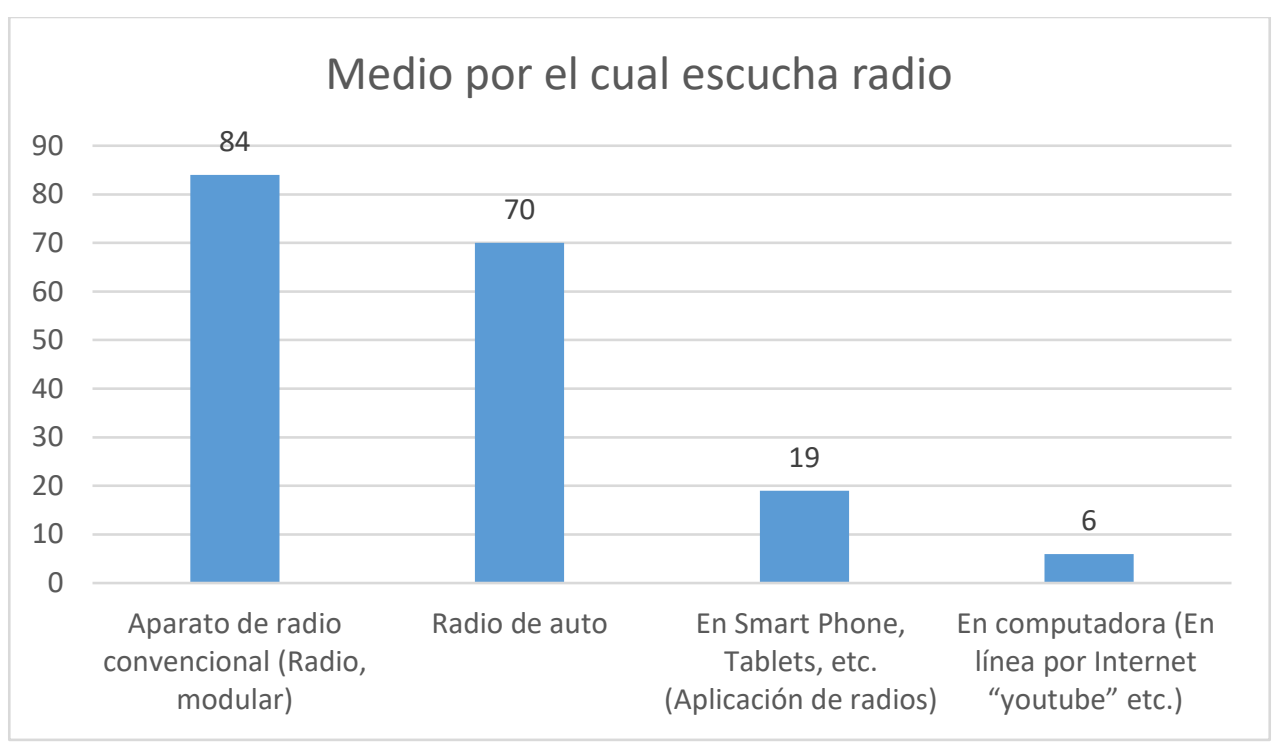

Fuente: Elaboración propia en base al Instrumento de investigación aplicado del 7 al 18 de Marzo del 2020, en Navojoa Sonora

A la pregunta sobre el medio que utilizan los entrevistados para escuchar radio, el $47 \%$ comentó que lo hace por radio convencional, el 39\% por el radio de su auto, el 10\% por medio de aplicación y el 3\% por computadora. Cabe mencionar que los entrevistados que usan más las aplicaciones son los del segmento entre 30 y 45 años. 
"Fl wher ile mis hijos

Año 13.
Revista de Investigación Académica sin Frontera ISSN: 2007-8870

http://revistainvestigacionacademicasinfrontera.com

Recibido el 10 de julio de 2020. Dictaminado mediante arbitraje favorablemente 14 de diciembre de 2020.

Figura 6 ¿Cuáles son las razones principales para escuchar radio?

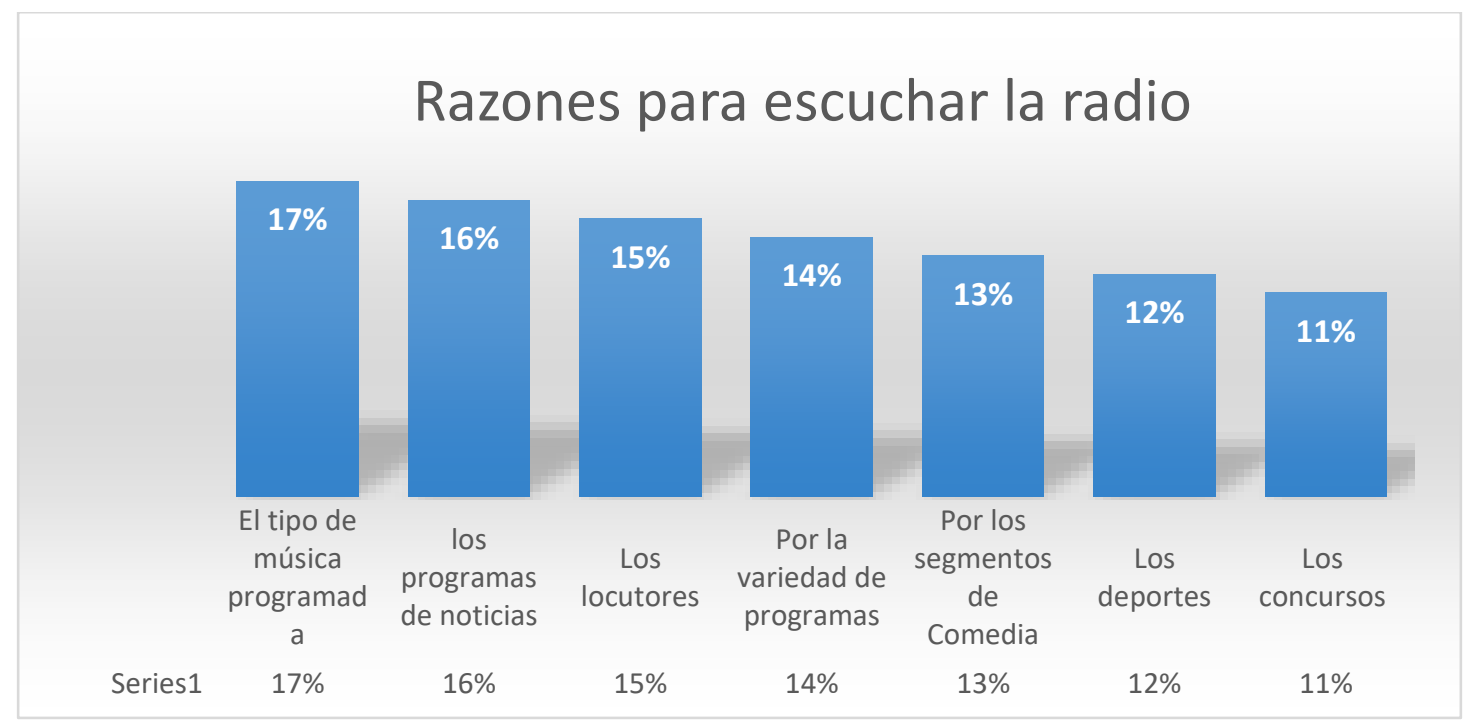

Fuente: Elaboración propia en base al Instrumento de investigación aplicado del 7 al 18 de Marzo del 2020, en Navojoa Sonora

Como se puede observar en la figura 6, las tres principales razones, mencionadas por los entrevistados, para escuchar la radio fueron: el tipo de música, los programas de noticias y los locutores. En cuarto lugar, la variedad de su música. En quinto, los segmentos de comedia seguido por los deporte en sexto lugar y los concursos en séptimo. 
Año 13.

Revista de Investigación

Núm. 33

\section{Académica sin Frontera}

ISSN: 2007-8870

\section{http://revistainvestigacionacademicasinfrontera.com}

Recibido el 10 de julio de 2020. Dictaminado mediante arbitraje favorablemente 14 de diciembre de 2020.

Figura 7 ¿Qué radiodifusora escucha?

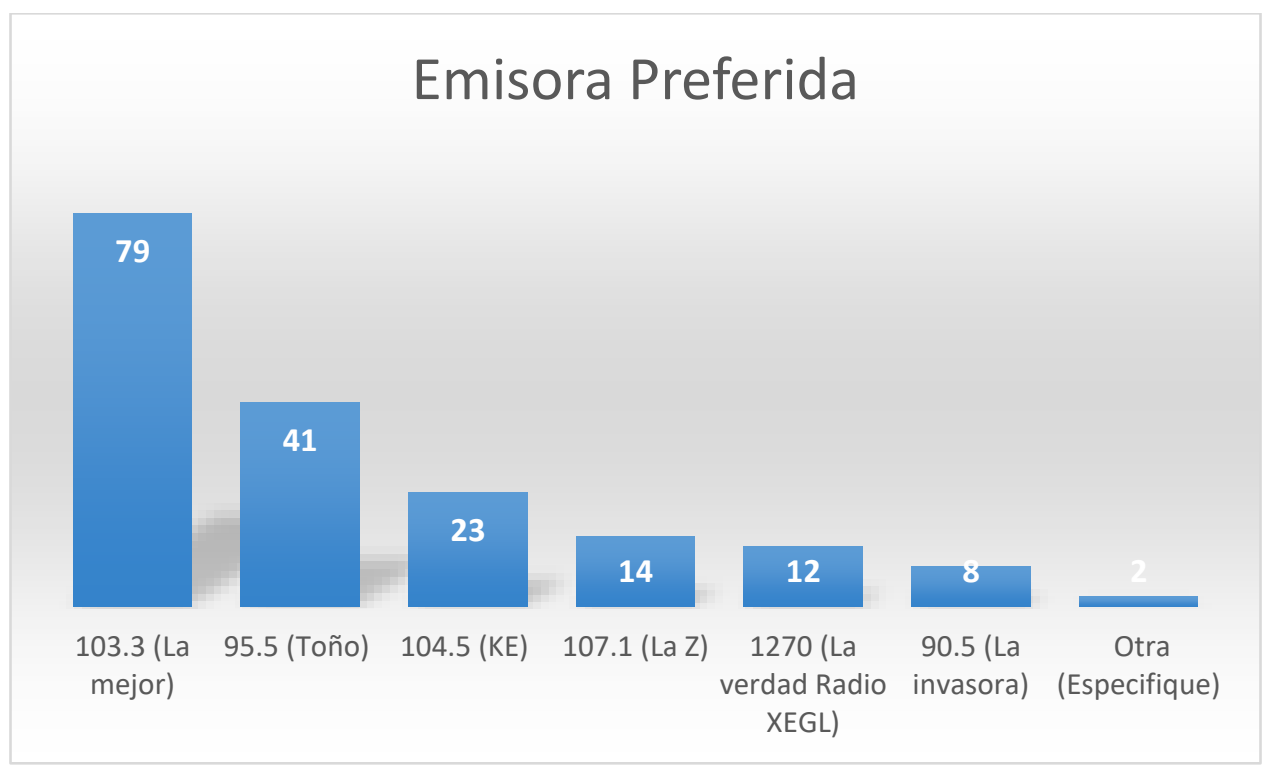

Fuente: Elaboración propia en base al Instrumento de investigación aplicado del 7 al 18 de Marzo del 2020, en Navojoa Sonora

Finalmente, para el público de Navojoa, Sonora la radio preferida, con el $44 \%$ de las menciones fue la 103.3 llamada la mejor, en segundo lugar está la 95.5, llamada Toño. En tercer lugar se encuentra la KE en el 104.4. En cuarto está la radio XEGL en el 1270 de AM. En quinto lugar la invasora en el 90.5 y finalmente se mencionó una radio llamada Estéreo rey escuchada por internet con el $1 \%$. 
Año 13.

Núm. 33

\section{http://revistainvestigacionacademicasinfrontera.com}

Recibido el 10 de julio de 2020. Dictaminado mediante arbitraje favorablemente 14 de diciembre de 2020.

\section{Conclusiones}

A continuación se presentan los resultados de la investigación donde se describen los factores que toman en consideración los radioescuchas para seleccionar una emisora de radio en la ciudad de Navojoa, Sonora. Se concluye que el segmento de población que más escucha radio es el de 30 a 45 años, siendo el rango de los 15 a los 29 los que menos lo hacían; revelándose que son más las mujeres quienes más escuchan las emisoras en Navojoa.

Se revela que los entrevistados que dijeron no escuchar la radio, no lo hacen debido a que no le agradan los programas actuales, que prefieren las redes sociales para informarse y algunos comentaron que no tienen tiempo para oírlo.

Se concluye que el $39 \%$ de los entrevistados escuchan la radio de tres a cinco días a la semana y que el $32 \%$ lo hace toda la semana.

Además, la mayoría de los entrevistados (72\%) escuchan la radio preferentemente en horarios matutinos y que lo hacen por lo menos una hora diaria (51\% de los entrevistados)

Se concluye que el $86 \%$ de los entrevistados escucha las emisoras a través de radios convencionales en casa y el auto. En el mismo sentido, se revela que solo el $10 \%$ escucha radio a través de aplicaciones, siendo esto un área de oportunidad que puede ser aprovechada por los radiodifusores dadas las tecnologías hoy disponibles.

Por otro lado, se determinó que en su mayoría el factor más relevante para el radioescucha para elegir su radio favorita es el tipo de música programada, seguido por los programas de noticias y los locutores. Sin embargo, en el segmento de edad entre 30 y 45 años, los principales factores fueron primero los programas de noticias, seguido del tipo de música y los locutores. 
Año 13.

Revista de Investigación

Núm. 33

Académica sin Frontera

ISSN: 2007-8870

\section{http://revistainvestigacionacademicasinfrontera.com}

Recibido el 10 de julio de 2020. Dictaminado mediante arbitraje favorablemente 14 de diciembre de 2020.

Finalmente se concluye que tres estaciones de radio concentran el $79 \%$ del mercado: La radio preferida por los navojoenses es la 103.3 llamada la mejor la cual fue la favorita del $44 \%$ de los encuestados, seguida por la radio 95.5 llamada Toño con el $23 \%$ de las preferencias, en tercer lugar fue para la KE en 104.4 con el $12 \%$ de las menciones.

\section{Referencias}

Diario Oficial de la Federación. (2016). Convocatoria para licitación pública para concesión de radiodifusión sonora. Recuperado de http://dof.gob.mx/nota_detalle.php?codigo=5441814\&fecha=20/06/2016

Fischer, L., \& Espejo, J. (2008). Mercadotecnia, Investigación de mercados. Recuperado de https://drive.google.com/file/d/0B4WZ4s-JRCyRQmE5VTVxSHkyc1k/view

Instituto Federal de Telecomunicaciones. (2018). Estudio de Cobertura de los Servicios de Radiodifusión en México. Recuperado dehttp://www.ift.org.mx/sites/default/files/contenidogeneral/espectro$\underline{\text { radioelectrico/Cobertura_de_los_servicios_de_radiodifusion_en_Mexico.pdf }}$

Mejía, F. (2007). Historia mínima de la radio mexicana (1920-1996). Recuperado de https://mexico.mom-rsf.org/uploads/tx_lfrogmom/documents/16-1329_import.pdf

Kinnear, T. y Taylor, J. (1998). Investigación de mercados, un enfoque aplicado. $3^{\mathrm{a}}$ Ed. Mc Graw Hill. México.

Pinoargote, M. (2007). Plan de Marketing para el reposicionamiento de radio la voz de la península. Recuperado de https://www.dspace.espol.edu.ec/bitstream/123456789/6780/1/PLAN\%20DE\%20M 
nFl ouber ide mis hijos

hará mi pronderio"

Año 13.

Núm. 33
Revista de Investigación Académica sin Frontera ISSN: 2007-8870

http://revistainvestigacionacademicasinfrontera.com

Recibido el 10 de julio de 2020. Dictaminado mediante arbitraje favorablemente 14 de diciembre de 2020.

\section{ARKETING\%20PARA\%20EL\%20REPOSICIONAMIENTO\%20DE\%20RADIO} \%20LA\%20\%20VOZ\%20DE\%20LA\%20PENINSULA.pdf

Herrera, S., "La participación de los oyentes en la programación de radio”, en MartínezCosta, M.P. (ed.), Reinventar la radio, Actas de las XV Jornadas Internacionales de la Comunicación,

Portilla, I. y Herrera, S. (2004). El mercado de la emisora: la audiencia. En Programación radiofónica (pp. 161-211). Barcelona: Ariel. 
"Fl siber dite min hijos

Año 13.

Núm. 33
Revista de Investigación Académica sin Frontera

ISSN: 2007-8870

http://revistainvestigacionacademicasinfrontera.com

Recibido el 10 de julio de 2020. Dictaminado mediante arbitraje favorablemente 14 de diciembre de 2020.

\section{Directorio Institucional}

Dr. Enrique Fernando Velázquez Contreras

Rector

Dr. Ramón Enrique Robles Zepeda

Secretario General Académico

Dra. Rosa María Montesinos Cisneros

Secretaria General Administrativa

Dr. Rodolfo Basurto Álvarez

Director de Vinculación y Difusión

Dra. Adriana Leticia Navarro Verdugo

Vicerrectora de la Unidad Regional Sur

Dr. Ernesto Clark Valenzuela

Director de la División de Ciencias Económicas y Sociales

Dr. Francisco Espinoza Morales

Secretario de la División de Ciencias Económico y Sociales

Dra. Leticia María González Velásquez

Jefe del Departamento de Ciencias Económico Administrativas

Dra. Lidia Amalia Zallas Esquer

Jefe de Departamento de Ciencias Sociales 
Año 13.

Revista de Investigación

Núm. 33

Académica sin Frontera

ISSN: 2007-8870

http://revistainvestigacionacademicasinfrontera.com

Recibido el 10 de julio de 2020. Dictaminado mediante arbitraje favorablemente 14 de diciembre de 2020.

\title{
Comité Directivo
}

\author{
Editor Responsable \\ Dr. Francisco Espinoza Morales \\ Universidad de Sonora \\ Directora \\ Dra. Leticia María González Velásquez \\ Universidad de Sonora \\ Subdirector \\ Dr. Javier Carreón Guillen \\ Universidad Nacional Autónoma de México \\ Editor Científico \\ Dr. Cruz García Lirios \\ Universidad Autónoma del estado de México \\ Master Gráfico \\ M.T.I. Francisco Alan Espinoza Zallas \\ Universidad Estatal de Sonora
}

Nos complace anunciar que su diario, "Academic Research Journal Withoutborders" (ISSN/EISSN 2007-8870) fue evaluado positivamente en la indexación Citefactor, ahora la página de la revista está disponible en línea, en caso de cualquier problema.

Journals Master | International Innovative Journal Impact Factor (IIJIF)

Red Latinoamericana de revistas Académicas en Ciencias Sociales y Humanidades
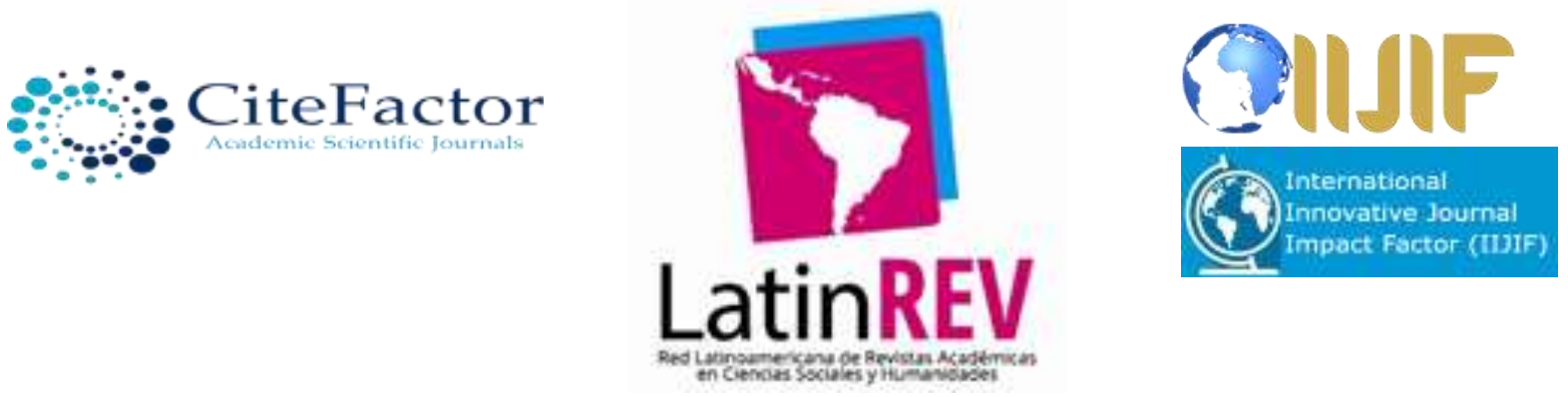

\section{Comité editorial}


Año 13.

Revista de Investigación

Núm. 33

Académica sin Frontera

ISSN: 2007-8870

\section{http://revistainvestigacionacademicasinfrontera.com}

Recibido el 10 de julio de 2020. Dictaminado mediante arbitraje favorablemente 14 de diciembre de 2020.

Dra. Angélica María Rascón Larios

Universidad de Sonora. México

Dra. María del Rosario Molina González

Universidad de Sonora

Dra. Francisca Elena Rochin Wong

Universidad de Sonora. México

Dra. Lidia Amalia Zallas Esquer

Universidad de Sonora. México

Dra. Beatriz Llamas Arechiga

Universidad de Sonora. México

Dr. Rogelio Barba Álvarez

Universidad de Guadalajara. México

Dra. Rosa María Rincón Ornelas

Universidad de Sonora. México

Dr. Juan Flores Preciado

Universidad de Colima. México

Dr. Amado Olivares Leal. Universidad de Sonora

Universidad de Sonora. México

Dr. Guillermo Velázquez Valadez.

Instituto Politécnico Nacional (IPN) México

Dr. Hugo Nefstalí Padilla Torres.

Universidad Estatal de Sonora. México

Dr. Luis Ramón Moreno Moreno.

Universidad Autónoma de Baja California. México

Dr. Miguel Ángel Vázquez Ruiz.

Universidad de Sonora. México

Dra. Lorena Vélez García.

Universidad Autónoma de Baja California. México 


\section{http://revistainvestigacionacademicasinfrontera.com}

Recibido el 10 de julio de 2020. Dictaminado mediante arbitraje favorablemente 14 de diciembre de 2020.

Dra. Pabla Peralta Miranda.

Universidad Simón Bolívar, Barranquilla, Colombia

Mtro. Roberto Espíritu Olmos

Universidad de Colima (FCA Tecomán) Colima

Dr. Héctor Priego Huertas.

Universidad de Colima (FCA Tecomán) Colima

Mtra. María Guadalupe Alvarado Ibarra.

Universidad de Sonora. México.

MSc. Celso Germán Sánchez Zayas

Universidad de Camagüey, Ignacio Agramonte Loynaz, Cuba

Dra. María Luisa Quintero Soto

Universidad Autónoma del Estado de México

Dr. Eyder Bolivar Mojica

Universidad Católica, Luis Amigó, Medellin, Colombia

Revisores de Textos en Inglés

Mtro. Renato Encinas

Mtra. Cecilia Guadalupe Martínez Solano

\section{Comité científico}

Dr. Rosendo Martínez Jiménez. Universidad Autónoma Benito Juárez de Oaxaca.

Dr. Hugo Neftalí Padilla. Universidad Estatal de Sonora

Dra. María Teresa Gaxiola Sánchez. Universidad de Sonora.

Dr. José Cesar Kaplan. Universidad Estatal de Sonora.

Dr. Alfredo Islas Rodríguez. Universidad de Sonora

Frecuencia de publicación: semestral / 2 números por año. 


\section{http://revistainvestigacionacademicasinfrontera.com}

Recibido el 10 de julio de 2020. Dictaminado mediante arbitraje favorablemente 14 de diciembre de 2020.

Revista de Investigación Académica sin Frontera (RIASF) con (ISSN: 2007-8870) es un interlocutor internacional de acceso abierto revisado diario en línea en el ámbito del de las Ciencias Económicas Administrativas y Sociales. Su objetivo principal es dar a los trabajos de investigación de calidad. Cubre todas las sub-campos de los campos anteriormente mencionados. Proporciona la plataforma a académicos, estudiantes y profesionales. Sólo pública trabajos de investigación y artículos de revisión inicial. Documento presentado debe cumplir con algunos criterios como, debe ser original, inédita y no estén sometidos a ninguna otra revista.

RIASF es una revista arbitrada / Revisión por pares International. Publicamos documentos sobre una variedad de temas, contextos y estrategias de análisis que examinan la relación entre la rápida evolución para la Sociedad y la tecnología del conocimiento.

REVISTA DE INVESTIGACIÓN ACADÉMICA SIN FRONTERA, Año 13, No. 33, Julio - diciembre 2020, es una publicación semestral de investigación científica, editada por la Universidad de Sonora, a través de las División de Ciencias Económicas y Sociales, de la Unidad Regional Sur, Blvd. Lázaro Cárdenas No. 100, Col. Francisco Villa, Navojoa, Sonora, Sonora, México, C.P. 85880. Tel. (642) 42599-54.

http://www.revistainvestigacionacademicasinfrontera.com/, revistaacademicasinfrontera@ unison.mx. Editor responsable: Francisco Espinoza Morales. Reserva de Derechos al Uso Exclusivo: 042013-121811323700-203 e ISSN: 2007-8870, ambos otorgados por el Instituto Nacional de Derecho de Autor. Inscrita en el Directorio de LATINDEX, con Núm. De folio 20014, folio único 14590. Responsable de la última actualización de este Número, Unidad Informática de la Universidad de Sonora, fecha de la última modificación, 30 de diciembre 2020, indexada a Cite Factor Academic Scientific Journal y Journals Master (IIJIF) y Red Latinoamericana de Revistas Académicas en Ciencias Sociales y Humanidades, (Latín Rev). Las opiniones expresadas por los autores no necesariamente reflejan la postura del editor de la publicación. Se autoriza la reproducción total o parcial de los contenidos e imágenes en la presente publicación siempre y cuando se cuente con la autorización del editor y se cite plenamente la fuente. 
Año 13.

Revista de Investigación

Núm. 33

Académica sin Frontera

ISSN: 2007-8870

http://revistainvestigacionacademicasinfrontera.com

Recibido el 10 de julio de 2020. Dictaminado mediante arbitraje favorablemente 14 de diciembre de 2020.

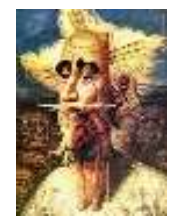

Nos complace anunciar que su diario, "Academic Research Journal Withoutborders" (ISSN/EISSN 2007-8870) fue evaluado positivamente en la indexación Citefactor, ahora la página de la revista está disponible en línea, en caso de cualquier problema.

Journals Master | International Innovative Journal Impact Factor (IIJIF)

\section{Red Latinoamericana de revistas Académicas en Ciencias Sociales y Humanidades}
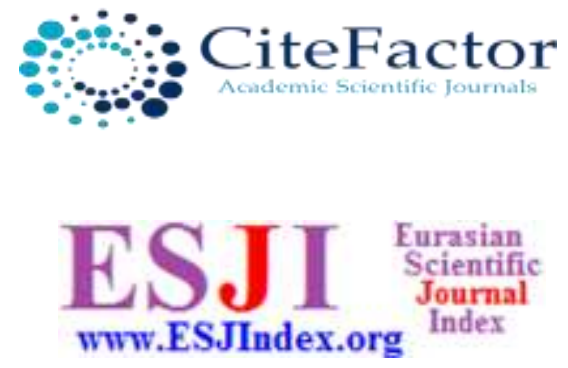

https://www.neliti.com

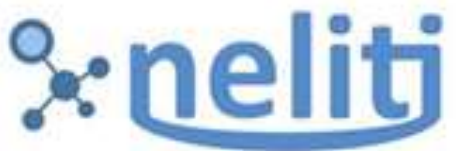

Indonesia's Research Repository

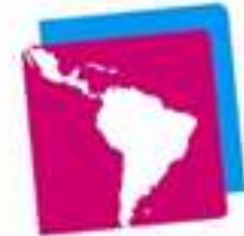

LatinREV
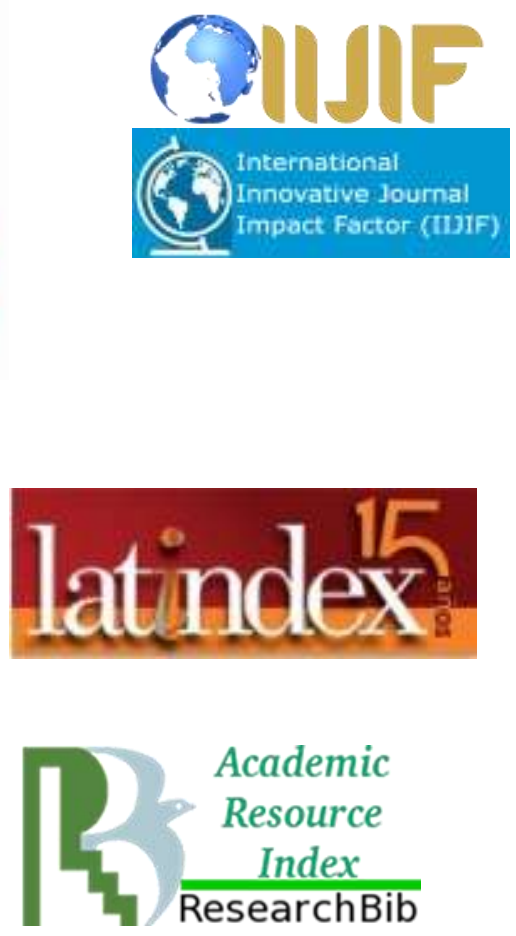